\title{
From Einstein's intuitions to quantum bits: amazing entanglement
}

\section{Alain Aspect}

Alain Aspect, "From Einstein's intuitions to quantum bits: amazing entanglement," Proc. SPIE 9664, Ninth International Topical Meeting on Education and Training in Optics and Photonics, 96642D (24 October 2005); doi: $10.1117 / 12.2207760$

SPIE Event: Ninth International Topical Meeting on Education and Training in Optics and Photonics, 2005, Marseille, France 
This paper is freely available as a resource for the optics and photonics education community.

\section{Ref ETOP077}

\section{From Einstein's intuitions to quantum bits: amazing entanglement}

\section{Alain ASPECT}

\section{Abstract}

In 1935, Einstein discovered entanglement, an amazing property of quantum mechanics which contradicted his world views. An intense debate with Niels Bohr followed, and was settled only after the discovery by John Bell of the famous inequalities named after him. Bell's theoretical work stimulated experiments, nowadays accessible to university laboratory classes, which demonstrate that entangled twin photons remain a single global object even when at a distance. We must take this conceptual revolution into account in our quantum description of the world. Applications of entanglement are also on the way, and a new field of research, Quantum Information, uses entanglement to develop applications as quantum cryptography and quantum computing. It may well be that we are living a second quantum revolution, which might change our society as strongly as the first quantum revolution did, when it gave us the laser and the transistor (and integrated circuits) at the root of the information and communication society. 